\title{
Polytransductant Formation in Escherichia coli Lysogens
}

\author{
By I. OLSEN* AND K. PAIGEN \\ Department of Experimental Biology \\ Roswell Park Memorial Institute, Buffalo, New York, 14203, U.S.A.
}

(Received 28 March 1972)

\begin{abstract}
SUMMARY
When a strain of Escherichia coli lysogenic for $\lambda$ and deleted for the gal operon was infected with $\lambda d g$ two types of $\mathrm{gal}^{+}$transductants arose, an expected class with enzyme levels similar to wild-type, and a exceptional class with elevated levels of enzyme and altered staining reactions on indicator plates. Transductants of the exceptional class appear to carry multiple copies of a homoimmune $\lambda d g$ prophage. When exceptional transductants were prepared carrying a $t s$ kinase mutation in their $\lambda d g$ and then selected for ability to grow at high temperatures, two types of $\lambda d g$ could subsequently be isolated from the temperature-resistant revertants, one carrying a temperature-resistant and the other a temperaturesensitive kinase gene. It has been possible to infer the existence of polytransductants containing more than two transducing prophage by their segregation patterns. The rate at which such cells produce phage, after u.v. induction, in a medium with galactose as the sole carbon source, is accounted for by the polytransductant structure.
\end{abstract}

Polytransductant cells arose following infection by $\lambda d g$ at very low multiplicities. Identification of prophage types after mixed infection with genetically marked $\lambda d g$ 's showed that each polytransductant carried only one type of transducing phage. When the superinfecting transducing phage was unable to make active $\lambda$ repressor, as is the case for $\lambda p g_{8} \mathrm{C}_{1} 857$ at high temperature, the frequency of polytransductant formation was enhanced. Inhibition of protein synthesis with chloramphenicol also enhanced polytransductant formation. These experiments suggest that, at least in the case of $\lambda d g$, limited phage replication does take place in immune hosts, and is followed by multiple integrations into the bacterial chromosome.

\section{INTRODUCTION}

Appleyard (1953, 1954) initially described the formation of Escherichia coli cells containing more than one $\lambda$ prophage. Such polylysogens have readily been obtained following infection of sensitive bacteria at high multiplicities of infection (Arber, 1960; Freifelder \& Kirschner, I97I), suggesting that they arise in cells that have absorbed more than one phage. Alternatively, intracellular phage replication can result in a vegetative pool (Brooks, I965) from which multiple phage genomes can be integrated into the bacterial chromosome before the establishment of lysogenic immunity. Superinfected lysogens form polylysogens infrequently when the recipient lysogen harbours a homoimmune prophage, but more readily if it harbours a prophage of different immunity (Calef, Marchelli \& Guerrini, 1965).

The integration of $\lambda d g$ into sensitive cells is appreciably less frequent than that of $\lambda$. Simultaneous infection with $\lambda$ increases this frequency (Arber, Kellenberger \& Weigle, 1957; Campbell, 1957). The frequency of $\lambda d g$ integration is also increased by the presence

* Present address: Department of Immunology, St Mary’s Hospital Medical School, London, W.2. 
of a resident $\lambda$ prophage, especially if it is a heteroimmune one (Campbell \& Balbinder, 1959).

In the course of physiological experiments involving $\lambda d g$ transduction, we have noted the occurrence of $\mathrm{gal}^{+}$transductants which by genetic means are shown to contain more than one transducing phage genome. These $\lambda d g$ polytransductants arose after superinfection by single $\lambda d g$ particles of homoimmune lysogens. Their formation indicates that at least limited phage replication can occur even under immune conditions. Once multiple copies are present, the integration of multiple $\lambda d g$ prophages is predicted by the results of several recent studies (Gingery \& Echols, I967; Guerrini, I969; Weisberg \& Gottesman, 1969) on the recombination regions of phage, host and prophage ends.

Dr R. Elliott of this department has simultaneously isolated similar cells by an independent procedure and will report her results separately.

\section{METHODS}

Strains. The bacterial strains used are described in Table I. Unless otherwise indicated, wild-type $\lambda$ was the phage employed. The $\lambda d g a l^{+}$was the isolate $\lambda d g 70.4$ of Weigle (I96I). $\lambda$ pgal 8 was isolated by S. Adhya (unpublished) by thermal induction of a $\lambda \mathrm{C}_{\mathrm{I}} 857$ lysogen carrying a $c h l D$-blu deletion. It is both plaque-forming and galactose-transducing, and makes no active repressor at $39^{\circ} \mathrm{C}$.

The $\lambda$ dgal ts mutants used to prepare strains IO-20, IO-2 I, IO-30 and IO-3I were isolated as follows. $\mathrm{w}_{3} 805$ is a gal $E$ point mutant lacking UDP galactose-4-epimerase function, whose growth is inhibited by the accumulation of UDP galactose when galactose is present in the medium. An exponential phase culture growing in M9 (see Media) glycerol was mutagenized with methyl-nitro-nitrosoguanidine ( $100 \mu \mathrm{g} / \mathrm{ml}$, I $5 \mathrm{~min}, \mathrm{I} \%$ survival) and the survivors plated on $\mathrm{M} 9$ plates containing both glycerol and galactose and incubated at $42{ }^{\circ} \mathrm{C}$. After 3 days colonies appeared on the plates; $20 \%$ were large, the remainder small. All of the large colonies were resistant to galactose at both $30{ }^{\circ} \mathrm{C}$ and $42{ }^{\circ} \mathrm{C}$. Of these, $75 \%$ were galactose positive at both temperatures and are probably galE ${ }^{+}$revertants. The remainder of the large resistant colonies were galactose-negative at both temperatures and probably resulted from a second, temperature-insensitive mutation in galK, since loss of galactokinase makes galE mutants resistant to galactose. Among the small colonies 2/50 were galactose-resistant at $42{ }^{\circ} \mathrm{C}$ but not at $30{ }^{\circ} \mathrm{C}$, presumably because they carried a temperaturesensitive mutation in galK. One of the temperature-sensitive mutants was cloned, grown in $\mathrm{M}_{9}$ glycerol, again mutagenized with methyl-nitro-nitrosoguanidine, and plated on $\mathrm{M} 9$ galactose plates at $30{ }^{\circ} \mathrm{C}$ to select for $\mathrm{galE}^{+}$revertants. Two revertants were selected whose behaviour is in accord with their being $\mathrm{galK} t \mathrm{t}$, $\mathrm{galE}^{+}$. They were galactose-positive at $30^{\circ} \mathrm{C}$ but not at $42{ }^{\circ} \mathrm{C}$ and were galactose-resistant at both $30{ }^{\circ} \mathrm{C}$ and $42{ }^{\circ} \mathrm{C}$. Both clones were red if grown on C-TTC galactose plates (see Media) at $30^{\circ} \mathrm{C}$ and nearly white on these plates if grown at $42{ }^{\circ} \mathrm{C}$; if plates incubated at the higher temperature were transferred to $30{ }^{\circ} \mathrm{C}$ the colonies became dark red within 2 to $3 \mathrm{~h}$. The two clones were infected with $\lambda$ and lysogenic survivors isolated. From these lysogens low-frequency transducing lysates were prepared by u.v. induction; these lysates were used to transduce a gal deletion strain that was lysogenic for $\lambda(\mathrm{IO}-5)$ to galactose positive at $30^{\circ} \mathrm{C}$. Two galactose-positive transductants were isolated, IO-20 and IO-2 I, that after u.v. irradiation gave lysates transducing a temperature-sensitive ability to ferment galactose at high frequency.

When lysates from IO-20 and IO-2 I were allowed to infect IO-5 and the survivors plated on C-TTC galactose plates at $30{ }^{\circ} \mathrm{C}$, two types of galactose-positive transductants were 
Table I.

\begin{tabular}{|c|c|}
\hline Strain & Origin \\
\hline w3350 & Lederberg via Weigle \\
\hline w3805 & Lederberg \\
\hline B78A & Buttin \\
\hline SAI 65 & Adhya \\
\hline SA242 & Adhya \\
\hline $\mathrm{SA} 324$ & Adhya \\
\hline $10-5$ & This paper \\
\hline IO-IO & This paper \\
\hline IO-I I & This paper \\
\hline IO-20 & This paper \\
\hline IO-2 I & This paper \\
\hline IO-30 & This paper \\
\hline IO-3I & This paper \\
\hline Q368 & This paper \\
\hline Q369 & This paper \\
\hline $\mathrm{IO}-40$ & This paper \\
\hline $\mathrm{IO}-4 \mathrm{I}$ & This paper \\
\hline $\mathrm{IO}-42$ & This paper \\
\hline
\end{tabular}

Characteristics

gal $K^{-} T-E^{+}$, not lysogenic for $\lambda$

gal $K^{+} T^{+} E^{-}$, not lysogenic for $\lambda$. Same as QIOI

$F^{-}$thr- leu- thi- lac $Y^{-}$str $r$ gal $R$. A C600 derivative lysogenic for $\lambda$

$F^{-} h i s^{-}(g a l)_{d e l}$ lysogenic for $\lambda$. Lacks all of the gal operon except the distal end of the $K$ gene

$F^{-} \operatorname{str} r(\mathrm{gal}-\lambda)\left(_{\text {del }} \mathrm{I} 42\right)$. Lacks all of the gal operon except the distal end of the $K$ gene, and is deleted for all $\lambda$ prophage genes through $E$

$F^{-}$str $r$ his $^{-}$(aro G-gal-chlD-x) del lysogenic for $\lambda \mathrm{C}_{\mathrm{I}} 857$

SA242 lysogenized with $\lambda$ wild-type

$\mathrm{gal}^{+}$transductant of IO-5 with unusual colonial morphology on C-TTC gal. Presumed polytransductant for $\lambda d g$

Same as IO-IO

gal ts transductant of IO-5 with normal colonial morphology on C-TTC gal at $30^{\circ} \mathrm{C}$

Same as IO-20

gal ts transductant of IO-5 with exceptional colonial morphology on C-TTC gal at $30^{\circ} \mathrm{C}$. Presumed polytransductant for $\lambda d g$

Same as $10-30$

$\lambda d g$ transductant of IO-5. Normal colonial morphology

SA242 transduced to gal ${ }^{+}$with $\lambda$ dgal $O^{c}$. The gal $O^{c}$ mutation was obtained from Buttin's $\mathrm{C} 8 \mathrm{I}-2$, an $\mathrm{HfrH}$ strain

$\mathrm{gal}^{+}$transductant of IO-5 with unusual colonial morphology on C-TTC. Presumed to contain $3 \lambda p g_{8}$

Same as IO-40, but presumed to contain $2 \lambda p g_{8}$

$\lambda p g_{8}$ transductant of IO-5. Normal colonial morphology on C-TTC

obtained; most were dark red, but some were smaller and paler. Both types were white at $42{ }^{\circ} \mathrm{C}$. Two of the paler type were cloned as strains IO-30 and IO-3I. These were shown to have elevated levels of galactose enzymes as compared to IO-20 and IO-2I.

Phage techniques. Lysates of $\lambda d g$ were prepared by growing cultures in $\mathrm{M} 9$ galactose to $3 \times 10^{8}$ cells $/ \mathrm{ml}$, u.v. irradiating to a survival of $5 \%$, and incubating at $37^{\circ} \mathrm{C}$ for $3 \mathrm{~h}$, at which time visible lysis occurred. The incubation time was extended to $4 \mathrm{~h}$ when $30^{\circ} \mathrm{C}$ lysates were prepared. The lysates were treated with $\mathrm{I} \% \mathrm{CHCl}_{3}$, centrifuged, the supernatant again treated with $\mathrm{CHCl}_{3}$, and filtered through $0.45 \mu \mathrm{m}$ membrane filters. Sterility was tested on tryptone broth plates. $\lambda p g_{8}$ lysates were prepared in a similar manner at $39{ }^{\circ} \mathrm{C}$.

$\lambda d g$ and $\lambda p g_{8}$ were titred on T-TTC plates by the agar overlay method using w 3350 as the indicator. Plates poured with indicator were spotted with $0.0 \mathrm{I} \mathrm{ml}$ drops of a test lysate. For $\lambda d g$ titrations, the spots received a second drop of $\lambda$ lysate prepared from the gal deletion IO-5 as helper phage. $\lambda d g$ was scored as red papillae. $\lambda p g_{8}$ was titred without $\lambda$ helper.

In those experiments in which the rate of phage production was measured, the cultures were grown to early exponential phase at $39^{\circ} \mathrm{C}$ on $\mathrm{M} 9$ glucose. They were harvested by 
centrifugation, resuspended in $M 9$ buffer, and aerated for $I$ h. After centrifuging they were resuspended in $\mathrm{M} 9$ buffer to a concentration of $\mathrm{I}$ to $3 \times 10^{8} \mathrm{cells} / \mathrm{ml}$. The cultures were titred on C-TTC, the dilutions sterilized with $\mathrm{CHCl}_{3}$, and the extracellular phage titred as described. The original cell suspensions were irradiated, transferred to flasks containing $0.2 \%$ galactose, and aerated at $39^{\circ} \mathrm{C}$. Samples were removed at the indicated interval, and the extracellular phage content determined after $\mathrm{CHCl}_{3}$ treatment.

Mass transductions were carried out with recipients grown to late exponential phase in M 9 maltose $(0.4 \%)$ to facilitate adsorption. Recipient cultures were concentrated by centrifugation, aerated for $\mathrm{I} h$ to exhaust endogenous reserves, and added to a concentration of 5 to $10 \times 10^{9} / \mathrm{ml}$ to lysates containing $10^{4}$ to $10^{5} \lambda d g / m l$ in $\mathrm{M} 9$ buffer. Adsorption was allowed to proceed for $2 \mathrm{~h}$, during which time there was no change in cell number and more than $95 \%$ of the input phage was adsorbed. The mixture was then diluted Ioofold into M $9 \mathrm{gal}$ and aerated until the culture reached stationary phase. This method was employed in the isolation of the polytransductants described below.

Enzyme induction. The gal operon was induced by adding $\mathrm{D}(+)$-fucose to a concentration of $4 \mu \mathrm{M}$ to exponential cultures growing in M 9 gylcerol. Galactokinase was used as the indicator enzyme and was assayed by a modification (Williams \& Paigen, 1969) of Sherman's (1963) procedure in which $\left[{ }^{14} \mathrm{C}\right]$ galactose is converted to $\left[{ }^{14} \mathrm{C}\right]$ galactose-Iphosphate and the reaction product trapped on ion-exchange paper and counted. Galactokinase units are expressed as $\mu \mathrm{M}$-galactose-I-phosphate formed/h. Culture densities are expressed as absorbance units at $550 \mathrm{nM}$ (using a Zeiss PMQ II spectrophotometer); one absorbance unit is approximately $240 \mu \mathrm{g}$ protein $/ \mathrm{ml}$. Enzyme induction curves are plotted using the method of 'relative growth' (Paigen \& Williams, I970).

Protein synthesis. In those experiments in which the effect of inhibition of protein synthesis was examined, the cell suspension and lysate were incubated for 15 min before mixing with 20 or $100 \mu \mathrm{g} / \mathrm{ml}$ of chloramphenicol.

Media. The synthetic medium used is similar to $\mathrm{M} 9$ (Anderson, 1946) and contained the following components/l: $\mathrm{Na}_{2} \mathrm{HPO}_{4} \cdot 7 \mathrm{H}_{2} \mathrm{O}, 13 \mathrm{~g} ; \mathrm{KH}_{2} \mathrm{PO}_{4}, 3 \mathrm{~g} ; \mathrm{NH}_{4} \mathrm{Cl}, \mathrm{I} \mathrm{g} ; \mathrm{NaCl}$, $0.5 \mathrm{~g} ; \mathrm{MgSO}_{4}, \mathrm{I} \mathrm{mM} ; \mathrm{FeCl}_{3}, 3 \mu \mathrm{M}$. Carbon sources were sterilized separately and added to a final concentration of $0.2 \%$. Synthetic solid medium was prepared by adding to the above mixture I $5 \%$ Difco Agar that had been extensively washed with water and ethanol.

Two types of galactose indicator plates were used. One, C-TTC galactose, was especially useful for discriminating between various galactose positive phenotypes and contained the following in $\mathrm{g} / 1$ : agar, $\mathrm{I} 5$; tryptone, 5 ; galactose, 10 ; yeast extract, $\mathrm{I} \cdot \mathrm{O}$ and triphenyltetrazolium chloride, 0.5 . The second, T-TTC galactose, was more useful for transductions and was prepared by omitting yeast extract from the above mixture and adding $5 \mathrm{~g} \mathrm{NaCl}$.

\section{RESULTS}

When strain IO-5, carrying a gal deletion and lysogenic for $\lambda$, was used as the recipient in a $\lambda d g$ transduction experiment, two types of red $\mathrm{gal}^{+}$colonies were found on C-TTC indicator plates. The majority type was dark red and identical in appearance to the colonies arising from wild-type cells. The other colony type, given by $x$ to $5 \%$ of the transductants, was somewhat smaller and distinctly lighter in colour. The appearance of these latter colonies was identical to those formed when the same parent strain received a $\lambda d g$ carrying a $\mathrm{gal}^{c}$ mutation. Both of these colony types are readily distinguished from those given by gal $R^{-}$constitutives, which are large and white with small dark red centres and those given by the gal deletion parent, which are almost white. 
Table 2. Enzyme levels in galactose mutant strains

Measurements were made on log-phase cultures after 8 to 12 generations of growth in each medium. Galactokinase activity is expressed as $\mu \mathrm{M}$-galactose-I-P formed/h/unit absorbance of culture. When present the concentration of fucose was $4 \times 10^{-3} \mathrm{M}$. Colonial morphology was determined on C-TTC gal plates. Q368 is the stock $\lambda d g$ transductant of IO-5. The normal transductant has been selected from the transduction experiments described in Methods. IO-5 itself shows no detectable enzyme levels.

\section{Strain}

gal $\Delta(\lambda, \lambda d g)[\mathrm{Q} 368]$

Normal transductant

Exceptional transductant [IO-IO]

Exceptional transductant [IO-I I] gal $\Delta\left(\lambda, \lambda d g O^{c}\right)[\mathrm{Q} 369]$ gal $R$ [B-78A]
Colonial morphology

Dark red

Dark red

Pale

Pale

Pale

White with dark centre
Galactokinase content after growth on

\begin{tabular}{|c|c|c|c|}
\hline & $\begin{array}{l}\text { Glycerol } \\
\text { plus }\end{array}$ & & \\
\hline Glycerol & fucose & Galactose & Glucose \\
\hline 0.08 & 0.75 & $1 \cdot 32$ & 0.07 \\
\hline 0.08 & 0.93 & $I \cdot 68$ & 0.07 \\
\hline 0.14 & I.99 & 1.90 & 0.11 \\
\hline 0.20 & $2 \cdot 20$ & $I \cdot 97$ & 0.14 \\
\hline $0.8 \mathrm{I}$ & $2 \cdot 49$ & $2 \cdot 67$ & 0.66 \\
\hline $3 \cdot 15$ & - & $2 \cdot 52$ & $I \cdot 39$ \\
\hline
\end{tabular}

When the dark 'wild-type' transductants were recloned they rarely, if ever, gave rise to a different colony type. However, when the exceptional colonies that appeared smaller and lighter were recloned, they segregated wild-type colonies at frequencies of $\mathrm{I}$ to $10 \%$. Two relatively stable clones of the exceptional type, designated IO-IO and IO-I I were selected for further study.

The exceptional strains IO-IO and IO-I I are not constitutive for the galactose enzymes despite their similarity to gal $O^{c}$ mutants in colonial morphology. Measurements of galactokinase levels were compared in $\mathrm{gal}^{+}, \mathrm{gal} \mathrm{O}^{c}$, gal $\mathrm{R}^{-}$, wild-type transductants, and exceptional transductants grown in different media (Table 2). The exceptional transductants are inducible, although in these two strains both the basal and fully induced levels of $\mathrm{gal}$ enzymes are 2 to 3 times those found in wild-type cells. Induction curves for strains IO-IO and IO-I I confirm these findings (Fig. I). The time course of induction is normal, but the differential rate of enzyme synthesis is elevated. Thus, the exceptional transductant clones, typified by IO-IO and IO-I I, represent genetically metastable states with several-fold elevations in the rates of both basal and induced enzyme synthesis. Although the rate of enzyme induction is greater in Q368 than in the selected normal transductant, the absolute levels are slightly lower (compare Table 2 with Fig. I). The reason for this discrepancy is not known.

Genetic origin of elevated enzyme forming capacity. The elevated enzyme levels in IO-IO and IO-I I are not the result of a mutation within the gal operon since this phenotype is not transduced by the $\lambda d g$ present in these strains. High-frequency transducing lysates were prepared from tryptone broth cultures of IO-IO and IO-I I as well as from cultures of normal transductants of the same parental gal deletion strain IO-5. Small drops of lysate containing a total of approximately $5 \times 10^{8} \lambda$ and $10^{6} \lambda d g$ were placed on T-TTC gal indicator plates seeded with IO-5. The confluent dark red areas of $\mathrm{gal}^{+}$transductants which arose were scraped and inoculated into $\mathrm{M} 9$ galactose and allowed to grow into stationary phase. This procedure yields a mixture of transductants from each original lysate. Control experiments showed that this procedure does not select against the unusual type of transductants. The galactose-grown cultures were streaked on C-TTC gal plates to determine the relative percentages of normal and exceptional transductants and were adapted to growth in glycerol to determine inducibility of the gal operon. 


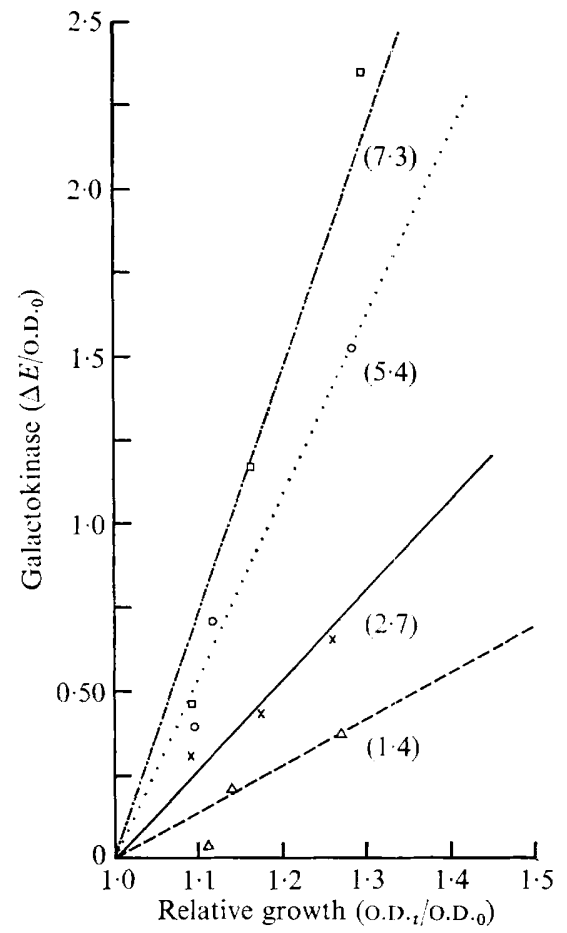

Fig. I

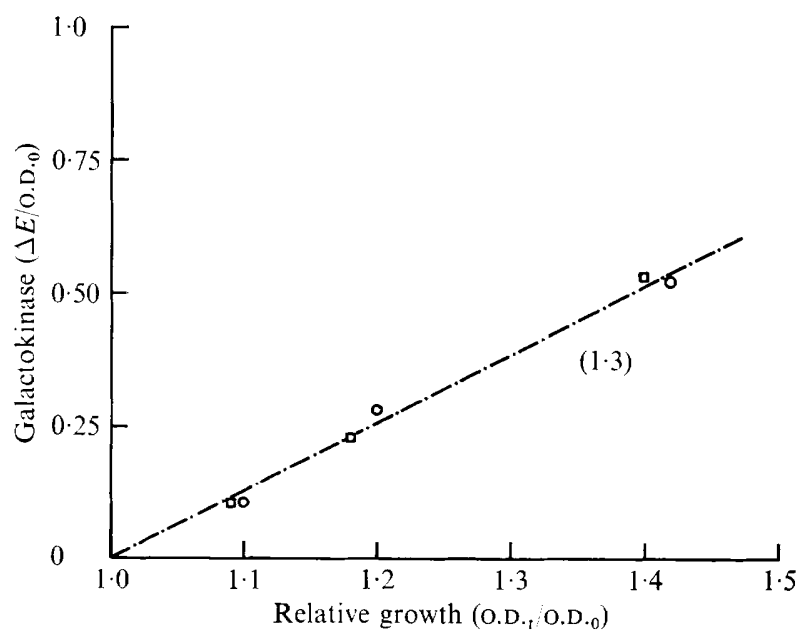

Fig. 2

Fig. I. Enzyme induction curves for unusual transductants. Experimental details are given in the Methods section. $O-\bigcirc$ and $\square-\square$ respectively are the unusual transductants IO-IO and IO-I I. $\triangle-\triangle$ is a normal transductant of IO-5, the recipient used in this experiment. $\times-\times$ is $\mathrm{Q} 368$, the parent strain providing the $\lambda d g$ used in this experiment. Numbers in parentheses are the steadystate rates of enzyme synthesis taken from the slopes of the plots.

Fig. 2. Enzyme induction curves for normal transductants receiving $\lambda d g$ from unusual transductants. Experimental details are given in the Methods section. $\bigcirc-\bigcirc$ and $\square-\square$ are normal transductants of IO-5 receiving their $\lambda d g$ from IO-IO and IO-I I respectively. Compare the steady-

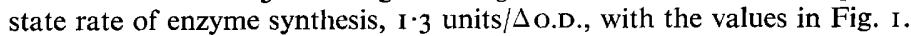

More than $95 \%$ of transductant colonies arising on the C-TTC gal test plates were wildtype in appearance regardless of which $\lambda d g$ donor supplied the gal operon. Measurements of enzyme induction (Fig. 2) confirmed this result; transductants receiving their $\lambda d g$ from IO-IO or IO-I I were no more inducible than those receiving $\lambda d g$ from a wild-type donor. We conclude that the genetic determinant for high inducibility does not lie within the gal operon or any other genetic region co-transduced with it by $\lambda d g$.

The genetic determinant for high inducibility does not appear to lie anywhere else in the Escherichia coli genome. Two gal negative segregants each were selected on C-TTC gal plates from IO-IO, IO-I I and a wild-type transductant. These six strains, which had lost their $\lambda d g$ but not their $\lambda$, were gal negative $\lambda$ lysogens. Each was used as the recipient for $\lambda d g$ present in the high-frequency transducing lysate obtained from the wild-type transductant. The experimental procedure was identical to that used in the preceding experiment. For every recipient, the final mixture of transductants obtained was again at least $95 \%$ wild-type in colonial morphology on C-TTC, and every mixture gave a wild-type rate of enzyme induction. We conclude that rapid inducibility is not determined by a genetic locus which remains in the $E$. coli genome after loss of $\lambda d g$. 
Table 3. $\lambda d g$ Production by temperature-resistant revertants of temperature-sensitive transductants

Revertants were selected for the ability to grow at $42{ }^{\circ} \mathrm{C}$ on $\mathrm{M} 9$ galactose. They were then grown at $30{ }^{\circ} \mathrm{C}$ and lysates prepared at this temperature. The lysates were then titered at $33{ }^{\circ} \mathrm{C}$ and $42{ }^{\circ} \mathrm{C}$.

\begin{tabular}{|c|c|c|c|c|}
\hline \multirow[b]{3}{*}{ Strain } & \multirow[b]{3}{*}{ Revertant } & \multirow{3}{*}{$\begin{array}{c}\lambda \text { when titred at } \\
33^{\circ} \mathrm{C}\end{array}$} & & \\
\hline & & & \multicolumn{2}{|c|}{$\lambda d g$ when titred at } \\
\hline & & & $33^{\circ} \mathrm{C}$ & $42{ }^{\circ} \mathrm{C}$ \\
\hline IO-20 & $\mathrm{d}$ & $6 \times 10^{5}$ & $4 \times 10^{5}$ & $6 \times 10^{5}$ \\
\hline IO-2I & a & $6 \times 10^{5}$ & $1 \cdot 6 \times 10^{3}$ & $8 \times 10^{2}$ \\
\hline $10-30$ & $\begin{array}{l}\mathrm{i} \\
\mathrm{f}\end{array}$ & $\begin{array}{l}\mathrm{I} \times 1 \mathrm{IO}^{5} \\
\mathrm{I} \times 10^{5}\end{array}$ & $\begin{array}{r}3.6 \times 10^{4} \\
3 \times 10^{4}\end{array}$ & $\begin{array}{r}2.1 \times 10^{4} \\
9 \times 10^{3}\end{array}$ \\
\hline IO-3I & $\begin{array}{l}\mathrm{i} \\
\mathrm{j} \\
\mathrm{l}\end{array}$ & $\begin{array}{r}1.3 \times 10^{5} \\
2.7 \times 10^{5} \\
3 \times 10^{5}\end{array}$ & $\begin{array}{r}1 \cdot 5 \times 10^{5} \\
3 \times 10^{6} \\
1.5 \times 10^{4}\end{array}$ & $\begin{array}{r}6 \times 10^{4} \\
4 \times 10^{5} \\
1 \cdot 2 \times 10^{3}\end{array}$ \\
\hline
\end{tabular}

These results suggest that rapid inducibility is a consequence of the manner of association of $\lambda d g$ with the host chromosome in IO-IO and IO-I I and not the result of a conventional mutation. One obvious possibility is that wild-type transductants contain a single $\lambda d g$ integrated into the bacterial chromosome, whereas highly inducible strains contain several $\lambda d g$ genomes inserted into the bacterial chromosome, thereby accounting for the elevated basal levels, hyperinducibility, and genetic instability of the exceptional strains.

Genetic evidence for polytransductants. We tested for the presence of multiple $\lambda d g$ 's in exceptional transductants by asking whether the selection of a gal operon mutation in these strains left them with two genetically different copies of the gal operon. The principal of the test is that $\mathrm{gal}^{+}$revertants selected from a gal ts lysogen carrying only one $\lambda d g$ should yield after induction only one type of $\lambda d g$, namely $\lambda d g a l^{+}$. However, $g a l^{+}$revertants selected from gal ts lysogens carrying several $\lambda d g$ 's should yield after induction two types of $\lambda d g$, namely those carrying the $g_{a l^{+}}$mutation selected for and those still carrying the parental gal ts gene.

The first step in this experiment was to isolate a $\lambda d g$ carrying a temperature-sensitive mutation in the gal operon which permitted growth on minimal galactose at $30^{\circ} \mathrm{C}$ but not at $42{ }^{\circ} \mathrm{C}$ (see Methods). Transductants carrying a single copy of this $\lambda d g t s$ were then prepared from the gal deletion lysogen, IO-5, by selecting transductants with normal phenotype on C-TTC plates at $30{ }^{\circ} \mathrm{C}$ (strains IO-20 and IO-2 I).

The next step was to prepare exceptional transductants that might carry several copies of $\lambda d g t s$. For this purpose high-frequency transducing lysates prepared from $\mathrm{IO}-20$ and IO-2 I were used to transduce the same gal deletion lysogen at $30^{\circ} \mathrm{C}$. On C-TTC gal plates at $30^{\circ} \mathrm{C}$, again the galactose-positive transductants gave both the large, dark red, wildtype colonies and a minority of the smaller, light red, unusual colonies. All transductants gave a white, galactose-negative, response at $42{ }^{\circ} \mathrm{C}$. Two of the exceptional colonies (deriving respectively from $\mathrm{IO}-20$ and $\mathrm{IO}-2 \mathrm{I}$ ) were selected and designated $\mathrm{IO}-30$ and IO-3I.

In the next step of the experiment $\mathrm{gal}^{+}$revertants were selected for growth on minimal galactose plates at $42{ }^{\circ} \mathrm{C}$ from IO-2O and IO-2I and from IO-3O and IO-3I. The revertants were grown at $30{ }^{\circ} \mathrm{C}$ and high-frequency transducing lysates prepared from them after u.v. irradiation. In every case the ability to metabolize galactose at $42{ }^{\circ} \mathrm{C}$ as well as at 


\section{Table 4. Transductants obtained using $\lambda d g$ from revertants of normal and exceptional transductants}

Lysates of revertants IO-20 (d), IO-30 (i) and IO-3I (j) of Table 3 were used to transduce a gal deletion (IO-5) at $30^{\circ} \mathrm{C}$. Individual transductants were cloned at $30^{\circ} \mathrm{C}$, grown up in $\mathrm{M} 9$ galactose at $30^{\circ} \mathrm{C}$ and the resulting cultures titred on $\mathrm{M} 9$ galactose at $30^{\circ} \mathrm{C}$ and $42^{\circ} \mathrm{C}$.

Growth of transductant clone on minimal-galactose at $42{ }^{\circ} \mathrm{C}$ relative to its growth at $30^{\circ} \mathrm{C}$

Source of revertant supplying $\lambda d g$

\section{Transductant close}

I

Fraction positive at $42{ }^{\circ} \mathrm{C}$

I
2
3
4
5
6
7
8
9
0
1
2

$33^{\circ} \mathrm{C}$ was transducible by $\lambda d g$ (Table 3 ), indicating that all reversions had occurred within the gal operon itself, and were not the result of suppressor mutations elsewhere in the genome.

The last step of the experiment tested for the production of two types of $\lambda d g$ by revertants of IO-30 and IO-3I, the exceptional strains presumed to carry multiple $\lambda d g$ 's. For this, high-frequency transducing lysates were prepared at $30{ }^{\circ} \mathrm{C}$ from revertants of IO-30 and IO-3I and as a control from a revertant of IO-20, a strain carrying only one $\lambda d g$. Using each of these lysates 12 independent galactose-positive transductants of the $\mathrm{gal}$ deletion strain IO-5 were selected at $30^{\circ} \mathrm{C}$. Each independent transductant was cloned and then tested for whether it was $\mathrm{gal}^{+}$or $\mathrm{gal}$ ts by first culturing it in $\mathrm{M} 9 \mathrm{gal}$ at $30^{\circ} \mathrm{C}$, and then titring this culture on $\mathrm{M} 9 \mathrm{gal}$ plates at $30^{\circ} \mathrm{C}$ and $42{ }^{\circ} \mathrm{C}$. Whereas all of the transductants (I2/I2) derived from the revertant of the normal strain IO-20 were galactosepositive at $42{ }^{\circ} \mathrm{C}$, only some (3/II and 8/I2) of the transductants derived from revertants of the unusual strains IO-30 and IO-3I were positive at the elevated temperature (Table 4).

The observation that two types of $\lambda d g$ are produced by the revertants strongly indicates that these unusual strains do indeed contain two galactose operons. Furthermore, the equal frequency of incorporation of these operons into $\lambda d g$ suggests that both operons have an equivalent relationship to the Echerichia coli chromosome as far as phage formation is concerned, and that they may exist in a tandem arrangement.

Additional evidence that strains IO-30 and IO-3I contain two copies of the gal operon comes from the observation that these strains, but not IO-20 and IO-2I, spontaneously segregate a high proportion of clones that are temperature-sensitive galactose fermentors. These presumably have segregated the $\lambda d g$ carrying the temperature-insensitive mutation and retained the $\lambda d g$ carrying the temperature-sensitive gal operon.

The formation of polytransductants was not dependent on the genetic structure of the recipient strain used. They were obtained after $\lambda d g$ transduction of $\lambda$ lysogens of two other 
gal deletion strains, SAI 65 and SA324. The unusual phenotype was also obtained after $\lambda d g$ transduction of strain $\mathbf{w} 335^{\circ}$, which is neither a deletion nor a lysogen, but carries point mutation in both the gal $\mathrm{K}$ and gal $\mathrm{T}$ genes. They were also formed when the non-lysogenic deletion SA242 was simultaneously infected by $\lambda d g$ and $\lambda$, as well as when the $\lambda$ lysogenic derivative, IO-5, was superinfected with $\lambda d g$.

Multiple phage adsorption. The multiplicity of infection of $\lambda d g$ was generally below $\mathrm{IO}^{-4}$ in the transduction experiments that gave rise to cells carrying multiple $\lambda d g$ genomes, making it unlikely that these polytransductants arose from multiply infected cells. On the other hand, replication of $\lambda d g$ in a recipient lysogen of the same immunity should be severely repressed. This leaves the question of how the multiple $\lambda d g$ genomes originated. The following control experiments rule out multiple adsorption as a mechanism and suggest that some replication of $\lambda d g$ must occur in immune hosts.

Wild-type $\lambda d g$ and $\lambda d g a l t s, 5 \times 10^{4}$ per $\mathrm{ml}$ of each, were mixed and adsorbed to $\mathrm{IO}-5$ at $30{ }^{\circ} \mathrm{C}$. Immediately following adsorption the suspensions were centrifuged twice to remove any unadsorbed phage. After growth on $\mathrm{M} 9 \mathrm{gal}$ to stationary phase at $30^{\circ} \mathrm{C}$ the cultures were plated on C-TTC and $\mathrm{I} 6$ polytransductant colonies were selected. Each was grown to stationary phase on $\mathrm{M} 9 \mathrm{gal}$ at $30^{\circ} \mathrm{C}$ and titred on $\mathrm{M} 9 \mathrm{gal}$ plates at $30^{\circ} \mathrm{C}$ and $42{ }^{\circ} \mathrm{C}$. Five were temperature-sensitive and did not grow at the high temperature. The remaining I I temperature-resistant polytransductants would be expected to carry some temperature sensitive as well as temperature-resistant $\lambda d g$ prophages if they arose from multiply infected cells, but only temperature-resistant prophages if they arose from singly infected cells in which $\lambda d g$ replication had occurred.

Lysates of each of the 16 cultures were prepared and then used to infect strain IO-5. From each infection $8 \mathrm{gal}^{+}$transductants were selected at $30^{\circ} \mathrm{C}$ and then tested for growth at $30^{\circ} \mathrm{C}$ and $42{ }^{\circ} \mathrm{C}$ to determine whether they were $\mathrm{gal}^{+}$or gal ts. In every case all eight transductants arising in a single infection were of the same type; whether this was $\mathrm{gal}^{+}$ or gal ts depended upon the phenotype of the phage donor. As a control, temperatureresistant revertants were isolated from two of the temperature-sensitive polytransductants. As expected, phage from these revertants yielded a mixture of $\mathrm{gal}^{+}$and gal ts transductants.

Since none of the II temperature-resistant polytransductants carried any temperaturesensitive $\lambda d g$ prophages, it is concluded that they did not arise from cells that had adsorbed more than one transducing phage, but from cells in which intracellular phage multiplication occurred prior to integration, despite immune repression.

Formation of $\lambda p g_{8}$ polytransductants. The above experiments indicate that at least some replication of $\lambda d g$ occurs after superinfection of homoimmune lysogens. If a transducing phage that was itself defective in repressor synthesis was used the frequency of polytransductant formation was higher, with an apparent increase in the average number of prophages integrated. $\lambda p g_{8}$ carries the $\mathrm{C}_{1} 857$ mutation, making it unable to synthesize active repressor above $39^{\circ} \mathrm{C}$. When the homoimmune lysogen IO-5 was infected with this phage at $39{ }^{\circ} \mathrm{C}$, at least three and up to five morphological types of $\mathrm{gal}^{+}$cells appeared on C-TTC plates. They ranged from a deep red colony (IO-42), similar to the usual transductant obtained with $\lambda d g$, to a very large and nearly white colonial type (IO-40) that often accounted for nearly $10 \%$ of the $\mathrm{gal}^{+}$population. Upon restreaking, or following growth in liquid medium, this latter transductant segregated both normal colonies and an intermediate pink colony, $10-4 \mathrm{I}$, which also appeared during the original transduction procedure. IO-4I, in turn, segregated deep-red colonies identical to normal transductants, but rarely reverted to the original nearly white morphology.

Cultures of these transductants grown at $39{ }^{\circ} \mathrm{C}$, or u.v. irradiated and grown at $30{ }^{\circ} \mathrm{C}$, 


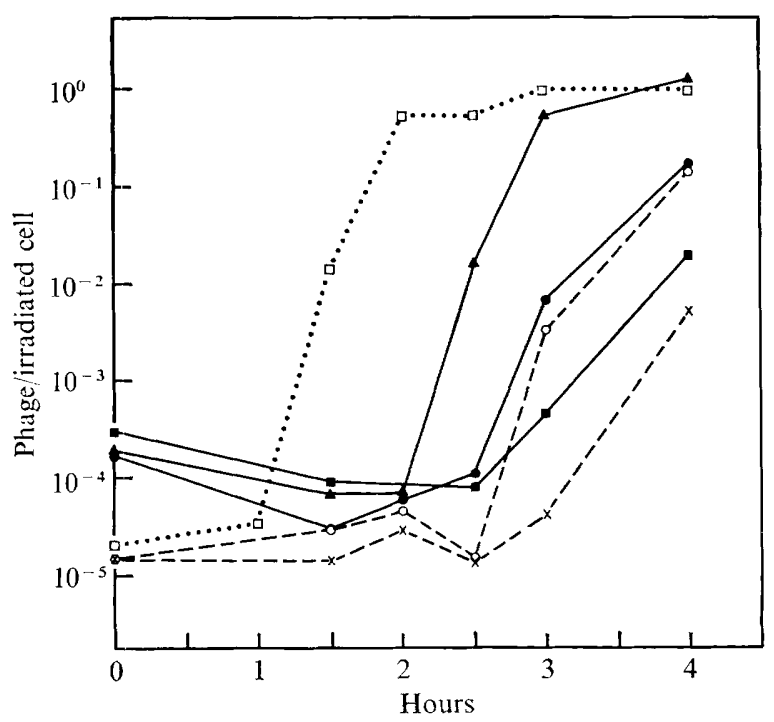

Fig. 3. Rate of phage production by $\mathrm{gal}^{+}$transductants of IO-5. Experimental details are given in the Methods section. The solid lines represent $\lambda p g_{8}$ transductants IO-40 $(\boldsymbol{\Delta}-\mathbf{\Delta}), \mathrm{IO}-4 \mathrm{I}(\mathbf{O}-\mathbf{O})$ and IO-42 (ם- $\mathbf{\square})$. The dashed lines represent $\lambda d g$ transductants Q368 $(\times-\times)$ and IO-IO $(\mathrm{O}-\mathrm{O})$. For each culture, the total number of transducing phage $/ \mathrm{ml}$ has been divided by the number of irradiated cells $/ \mathrm{ml}$ in that culture. The dotted line $(\square \ldots \square)$ shows the typical rate of phage production when any of the strains is grown on $\mathbf{M} 9$ galactose rather than $\mathbf{M} 9$ glucose.

show much higher concentrations of extracellular $\lambda$ and $\lambda p g_{8}$ than when grown without irradiation at $30^{\circ} \mathrm{C}$. Furthermore, transductant colonies appear nibbled at the high temperature. These observations are consistent with the replication of one phage chromosome, in spite of immunity, as part of a replicon driven by a second phage when the two phages are in tandem and the second phage ( $\lambda p g_{8}$ in this case) is induced. An analogous result was obtained by Thomas \& Mousset (I970) in a case where the two phages were not homoimmune.

Enzyme levels and phage production. The presence of more than two transducing prophages in the new class of polytransductants was tested by examining the relationship between levels of the galactose enzymes and rates of phage production in minimal galactose medium.

Initial experiments indicated that the rate at which extracellular $\lambda d g$ appeared, following irradiation of a normal transductant strain and transfer of the cells to $\mathrm{M} 9$ galactose, depended upon the culture conditions prior to irradiation. If the transductant was pregrown on galactose and had fully induced levels of galactose-metabolizing enzymes, progeny phage appeared rapidly (Fig. 3). Cells pregrown on glycerol, which contained only basal levels of enzyme, were slower to produce phage. If the cultures were pregrown on glucose, so that only catabolite-repressed levels of enzyme were present, then after irradiation and transfer to galactose phage production was delayed even further. The results in Table 2 demonstrate that cells containing more than one transducing phage (and hence more than one gal operon) contain higher enzyme levels than cells with only one transducing phage. Since the rate of phage production when galactose is the sole source of carbon depends upon the level of the galactose enzymes, cells containing increasing numbers of transducing phage should be distinguished by their rate of phage production. 
Three relatively stable morphological types of $\lambda p g_{8}$ transductants, IO-40, 4I, and 42 , together with a normal and polytransductant obtained with $\lambda d g$, were analysed in this manner (Fig. 3). Both IO-IO, which by genetic analysis carries two transducing prophage, and IO-4I, which from its segregation behaviour probably also carries two transducing prophage, produced phage more rapidly than the usual transductant with a single transducing prophage. IO-40, which by its segregation pattern appears to contain at least three transducing prophage-i.e. it segregates both the pink and dark red colonial types produces phage even more rapidly, confirming its possession of an increased number of gal operons.

Protein synthesis and polytransductant formation. Fry (1959) first observed that inclusion in broth medium of $15 \mu \mathrm{g} / \mathrm{ml}$ of chloramphenicol increased the frequency of the lysogenic instead of the lytic response of Echerichia coli $\mathrm{KI} 2$ to infection by $\lambda$. Under these conditions, protein synthesis was inhibited at least $95 \%$ and DNA synthesis $40 \%$. Young \& Sinsheimer (1967) have shown that $30 \mu \mathrm{g} / \mathrm{ml}$ chloramphenicol will allow both circularization and slow replication of infective DNA, although no mature viral DNA is formed. The inclusion of I $00 \mu \mathrm{g} / \mathrm{ml}$ allows the conversion of the injected DNA into the covalently closed circular duplex, but not DNA replication.

Under the conditions employed for the isolation of the transductants used in this work it may be presumed that protein synthesis, and most probably DNA synthesis as well, can take place at only low levels during the $2 \mathrm{~h}$ period of adsorption. With both types of phage, however, I to $5 \%$ of the transduced cells were found to contain more than one copy of the transducing particle. More severe restriction of protein synthesis by the inclusion of $20 \mu \mathrm{g} / \mathrm{ml}$ of chloramphenicol during the infection period resulted in an increase in the frequency of polytransductants up to $50 \%$ of the transduced cells in some experiments. The inclusion of $100 \mu \mathrm{g} / \mathrm{ml}$ had a similar effect, i.e. inhibition of protein synthesis favoured phage replication prior to integration.

\section{DISCUSSION}

The experiments reported in this work describe exceptional products of $\lambda d g$ transduction which occur at relatively high frequency. These unusual cells are recognized by a characteristic colonial morphology on C-TTC indicator plates. From their segregation pattern and by genetic analysis, we have shown them to carry multiple copies of the gal genome. Revertant temperature-resistant clones were selected from the presumed polytransductants carrying temperature-sensitive gal operons. Such temperature-resistant clones give rise to lysates of $\lambda d g$ able to transduce both temperature-sensitive and temperature-resistant galactose fermentation at high frequency. They also readily segregated temperature-sensitive galactose fermentors. From the work of Guerrini (1969) and others, it is suggested that these polytransductants may arise by int-mediated recombination between the $\mathrm{BP}^{\prime}$ attachment site of a $\lambda d g$ and one of the two $\mathrm{BP}^{\prime}$ regions present in a normal transductant. Rec-mediated (Clark \& Margulies, 1965; Brooks \& Clark, 1967) interstitial incorporation of one transducing phage genome into another cannot, however, be eliminated as a possibility by the results of these experiments.

The polytransductants are obtained following homoimmune superinfection of a $\lambda$ lysogen, at multiplicities of infection as low as $\mathrm{IO}^{-5}$. Multiple phage adsorption does not account for the presence of more than one transducing phage genome in the recipient, since mixed infection with temperature-sensitive and temperature-resistant $\lambda d g$ gives rise to polytransductants, each of which carries only one type of transducing phage. In contrast to the results of Wolf \& Meselson (1963) and Ogawa \& Tomizawa (I968) our experiments 
demonstrate that at least one round of phage DNA replication must frequently occur in immune cells. The formation of transductants with multiple prophage indicates that the low concentration of $\lambda$ repressor which is present in a lysogenic cell (Reichardt \& Kaiser, I97I) is not sufficient to inhibit completely all phage functions following homoimmune superinfection. In this regard, it is known that although the int gene is subject to negative control by the $\lambda$ repressor (Gottesman \& Yarmolinsky, 1967; Signer, 1970), functional levels of the int gene product must be present in immune cells since the site-specific integration of a single $\lambda d g$ into a homoimmune lysogen does occur (giving the gene order, determined by mapping, of - $g a l-\lambda d g-\lambda$-bio). It is presumably this system which also mediates the integration of additional transducing phage genomes to form the polytransductants described in this work.

When the superinfecting phage itself makes no active repressor, as in the case of a $\lambda p g \mathrm{C}_{1} 857$ mutant infecting at high temperature, polytransductants with three or more copies of the transducing phage genome were observed. They were identified by their segregation pattern on indicator plates and by observation that, when galactose is the sole source of carbon, the rate of production of phage after irradiation is dependent upon the number of gal operons present. In polytransductants with many transducing prophage, 'overtitration' of the $\lambda$ phage repressor followed by lysis may sometimes occur as evidenced by the high concentration of extracellular phage in transduced cultures as well as by the appearance of 'nibbled' transductant colonies. A similar overtitration phenomenon has been observed by Packman \& Sly (I968) and Sly \& Rabideau (I969) in their study of the virulence of the $\lambda \mathrm{C}_{17} \mathrm{C}_{\mathrm{I}}$ mutant in an immune host at high temperature. Pirrotta \& Ptashne (1969) have also noted this quantitative aspect of viral immunity on their report of the differences in behaviour of the $\lambda \mathrm{imm} 434 \mathrm{vir}$ mutant upon infection of homoimmune lysogens known to contain high and low levels of $\lambda$ imm 434 repressor.

The $\lambda$ repressor exerts a negative control over gene $N$ (Signer, 1970) whose product is required from the expression of $\lambda$ early functions. This repression cannot be total, however, since the replicative and integrative functions required for polytransductant formation are present in homoimmune lysogenic recipients. That only a low level of gene $N$ function would be required is indicated by the observations of Radding \& Echols ( I968) and Schwartz (1970). The presence of chloramphenicol, which increases the frequency of polytransductant formation, is known to result in hypertranscription of gene $N$ at a concentration of $100 \mu \mathrm{g} / \mathrm{ml}$ (Kumar et al. 1969). This escape synthesis would in turn allow increased replicative and integrative functions after the removal of chloramphenicol restored protein synthesis. The observation that even high concentrations of chloramphenicol stimulate polytransductant formation does not contradict the observations of Young \& Sinsheimer (1967) that this agent prevents DNA circularization and replication. It is probable that in our experiments genome replication and integration occurred in the period immediately after chloramphenicol removal when the cells were plated.

We are indebted to S. Adhya for the generous gift of the gal deletion strains and the $\lambda p g_{8}$ phage, and to Dr R. Elliott for encouraging discussions and communication of unpublished results. The help of Gordon Watson in completing these experiments is also gratefully acknowledged. This work was supported by grants from the National Science Foundation (GB-I2290) and the American Cancer Society (P-508), and by the School of Molecular Sciences, University of Warwick, Coventry. 


\section{REFERENCES}

Anderson, E. H. (1 946). Growth requirements of virus resistant mutants of E. coli strain 'B'. Proceedings of the National Academy of Sciences of the United States of America 32, 120-1 28.

APPlEyARD, R. K. (1953). Segregation of new lysogenic types during bacterial recombination in E. coli K12. Cold Spring Harbor Symposium of Quantitative Biology 18, 95-97.

APpleyard, R. K. (1954). Segregation of new lysogenic types during growth of a doubly lysogenic strain derived from Escherichia coli K12. Genetics 39, 440-452.

Arber, W. (1960). Polylysogeny for bacteriophage $\lambda$. Virology I1, 250-272.

Arber, W., Kellenberger, G. \& Weigle, J. (1957). La défectuosité du phage lambda transducteur. Schweizerische Zeitschrift für Pathologie und Bakteriologie 2o, 659.

Brooks, K. (1965). Studies in the physiological genetics of some suppressor-sensitive mutants of bacteriophage $\lambda$. Virology 26, 489-499.

BRooks, K. \& CLARK, A. J. (I967). Behavior of $\lambda$ bacteriophage in a recombination deficient strain of Escherichia coli. Journal of Virology r, 283-293.

Calef, E., Marchelli, C. \& Guerrini, F. (1965). The formation of super-infection-double lysogens of phage $\lambda$ in Escherichia coli $\mathrm{K}$ 2. Virology 27, $\mathrm{I}-\mathrm{IO}$.

CAMPBell, A. (1957). Transduction and segregation in Escherichia coli KI2. Virology 4, 366-384.

Campbell, A. \& Balbinder, E. (1959). Transduction of the galactose region of Escherichia coli KI 2 by the prophages $\lambda$ and $\lambda 434$ hybrid. Genetics $44,309-319$.

Clark, A. J. \& Margulies, A. D. (I 965). Isolation and characterization of recombination deficient mutants of Escherichia coli K I2. Proceedings of the National Academy of Sciences of the United States of America 53, 45 I-459.

Freifelder, D. \& KirSCHNER, I. (I97I). The formation of homoimmune double lysogens of phage $\lambda$ and the segregation of single lysogens from them. Virology 44, 633-637.

Fry, B. A. ( 1959). Conditions for the infection of Escherichia coli with lambda phage and for the establishment of lysogeny. Journal of General Microbiology 21, 676-684.

GingerY, R. \& Echols, H. (1967). Mutants of bacteriophage $\lambda$ unable to integrate into the host chromosome. Proceedings of the National Academy of Sciences of the United States of America 58, 1507-1514.

Gottesman, M. E. \& Yarmolinsky, M. B. (1968). Integration negative mutants of bacteriophage lambda. Journal of Molecular Biology 31, 487-505.

Guerrini, F. (1969). On the asymmetry of $\lambda$ integration sites. Journal of Molecular Biology 46, 523-542.

Kumar, S., Borre, K., Guha, A., Hradecna, Z., Maher, V. M. \& Szybalski, W. (i969). Orientation and control of transcription in Echerichia coli phage $\lambda$. Nature, London 221, 823-825.

Ogawa, T. \& Tonizawa, J. (I968). Replication of bacteriophage DNA. I. Replication of DNA of lambda phage defective in early functions. Journal of Molecular Biology 38, 2 1 7-220.

PaCkMan, S. \& SLY, W. S. (I968). Constitutive $\lambda$ DNA replication by $\lambda C_{17}$, a regulatory mutant related to virulence. Virology 34, $778-789$.

Paigen, K. \& Williams, B. (1970). Catabolite repression and other control mechanisms in carbohydrate utilization. Advances in Microbial Physiology 4, 25 I-324.

Pirrotta, V. \& Ptashne, M. (1969). Isolation of the 434 phage repressor. Nature, London 222, $541-544$.

Radding, C. M. \& Echols, H. (I968). The role of $N$ gene product of phage $\lambda$ in the synthesis of two phage-specified proteins. Proceedings of the National Academy of Sciences of the United States of America 6o, 707-7 I 1 .

ReichardT, L. \& KAISER, A. D. (1971). Control of $\lambda$ repressor synthesis. Proceedings of the National Academy of Sciences of the United States of America 68, $2185-2$ I 89.

Schwartz, M. (1970). On the function of the N cistron in phage lambda. Virology 40, 23-33.

Sherman, J. R. (1963). Rapid enzyme assay technique utilizing radioactive substrate, ion-exchange paper and liquid scintillation counting. Analytical Biochemistry 5, 548-554.

SIGNER, E. R. (1970). On the control of lysogeny in phage $\lambda$. Virology 40, 624-633.

SLY, W. S. \& RABIDEAU, J. (1969). Mechanism of $\lambda \mathrm{C}_{17} \mathrm{C}_{\mathrm{I}}$ virulence. Journal of Molecular Biology 42, 385-400.

Thomas, R. \& Mousset, S. (1970). Passive replication of heteroimmune bacteriophage in a $\lambda$-driven replicon. Journal of Molecular Biology 47, I79-191.

WeIGLE, J. ( I 96I ). Densities of transducing lambda bacteriophages. Journal of Molecular Biology 3, 393-398.

Weisberg, R. A. \& Gottesman, M. E. (1969). The integration and excision defect of bacteriophage $\lambda d g$. Journal of Molecular Biology 46, 565-580. 
Williams, B. \& Paigen, K. (I969). Relationships between the regulation of the lactose and galactose operons of Escherichia coli. Journal of Bacteriology 97, 769-775.

Wolf, B. \& MEselson, M. (1963). Repression of the replication of superinfecting bacteriophage DNA in immune cells. Journal of Molecular Biology 7, 636-644.

Young, E. T. \& SinsheIMER, R. L. (1967). Vegetative bacteriophage $\lambda$ DNA. II. Physical characterization and replication. Journal of Molecular Biology 30, 165-200. 